Revista de
Economila
Contemporâned

\title{
ESTADO E CAPITAL EM UMA CHINA COM CLASSES
}

\author{
Isabela Nogueira ${ }^{a}$ \\ aProfessora do Programa de Pós-Graduação em Economia Política Internacional \\ (PEPI) e coordenadora do Laboratório de Estudos em Economia Política da China \\ (LabChina), do Instituto de Economia da Universidade Federal do Rio de Janeiro.
}

Artigo recebido em 22/09/2017 e aprovado para publicação em 24/10/2017.

RESUMO: Este artigo complexifica o debate sobre o papel do Estado no desenvolvimento econômico ao lançar luz sobre uma dimensão muitas vezes ignorada na narrativa sobre o nacional-desenvolvimentismo na China: a relação do Partido-Estado com os capitalistas domésticos emergentes. Para tanto, nós analisamos os principais mecanismos utilizados para concentração de capital e formação de uma classe capitalista doméstica na China, evidenciamos a estreita relação dessa classe com o PartidoEstado e sugerimos como essa dinâmica se vincula com as mudanças no regime de acumulação. O objetivo é mostrar como o processo de formação da nova classe capitalista é uma via de mão dupla - um processo fortemente guiado pelo Partido-Estado, mas também sob crescente pressão da nova classe capitalista - e finamente articulado com o regime de acumulação de capital.

PALAVRAS-CHAVE: China; partido-estado; classe capitalista; acumulação de capital.

CLASSIFICAÇÃO JEL: O10; O53; P16. 


\title{
STATE, CAPITAL AND CHINA'S EMERGING CAPITALIST CLASS
}

\begin{abstract}
This article contributes to the debate on the role of the State in economic development by shedding light on a dimension quite often ignored in the narrative on national-developmentalism in China: the relation between the Party-State and its emerging capitalists. To that end, we analyze the main mechanisms used for capital concentration and the formation of a domestic capitalist class in China; we examine the relationship of the emerging class with the Party-State and we suggest how such dynamics is linked to the accumulation regime in a broader sense. The purpose is to show how the formation of a new domestic capitalist class is a two-way avenue - a process guided by the Party-State and under strong pressure from the new class - and how it is finely tuned with the accumulation regime.
\end{abstract}

KEYWORDS: China; party-state; capitalist class; capital accumulation. 


\section{INTRODUÇÃO'}

O problema seminal da economia política clássica e suas essenciais perguntas sobre as correlações e tensões entre a dinâmica de acumulação de poder e dinheiro sob o capitalismo ganhou relevância inconteste nos últimos anos e, de maneira particular, ao longo da crise política brasileira, que escancarou as ligações estreitas entre o político e o econômico. A falácia liberal de uma oposição generalizável entre Estados (interesses políticos) versus mercado (interesses econômicos), como campos distintos em batalha e irreconciliáveis, sendo a redução do Estado o resultado desejável, recuperou centralidade na luta ideológica e nas arenas política e midiática, apesar da completa ausência de evidências históricas de tal dicotomia na formação e constituição das sociedades industriais.

O Estado é, nas abordagens críticas da economia política (Marx), do institucionalismo crítico (Polanyi) e da longa duração (Braudel), uma forma social encrustada no seu movimento histórico. A acumulação capitalista não teria tido lugar sem o poder político de Estados centralizados, uma vez que a dinâmica de acumulação do capital é vitalmente emaranhada com a dinâmica de acumulação do poder político. Numa perspectiva estruturalista ou funcionalista, não apenas o Estado capitalista oferece o arcabouço regulatório, jurídico e repressor para que a propriedade privada, os contratos, o controle sobre a força de trabalho e a competição possam ocorrer; como tenta conter crises, oferecer alguma previsibilidade sobre o retorno do capital e guiar diretamente a acumulação de capital nas mais variadas formas (BRUNHOFF, 1979). Na ponta contrária, também o Estado capitalista depende da acumulação de capital para seu funcionamento e legitimidade, seja de maneira mecânica, por meio da arrecadação de impostos, ou da relação mais abstrata entre acúmulo de riqueza e aumento da capacidade de poder da nação. De maneira genérica, a competição capitalista contínua, o conflito de classe, as forças internacionais e as contradições geradas não apenas são determinadas pelas ações dos Estados capitalistas, mas também as determinam (COX, 1981; PANITCH e GINDIN, 2012).

O papel do Estado no processo de desenvolvimento capitalista ganha na China forma ainda mais explícita por conta da sua intervenção direta na acumulação de inúmeras formas - por meio de empresas estatais, políticas industriais amplas, planejamento diretivo, e estrito controle dos preços básicos (juros, câmbio e salários), dos fluxos internacionais de capitais e do sistema financeiro, para ficar no arcabouço eco-

\footnotetext{
A autora agradece pelas contribuições e comentários críticos de Bao Hong Juan, Carlos Aguiar de Medeiros, Célio Hiratuka, Eduardo Costa Pinto, Elias Jabbour, Fabiano Escher, Iderley Colombini, Tatiana Berringer e Valéria Ribeiro, e pela assistência de pesquisa de João Victor Guimarães.
} 
nômico mais macro. E, por razões históricas, essa relação entre Estado e acumulação é muito particular. A transição de uma economia socialista planificada para um "capitalismo de Estado com características chinesas" fez do ressurgimento da burguesia algo recente e particularmente imbricado com o Partido Comunista da China (PCC), cuja estrutura de poder está fundida com (mas hierarquicamente acima das) estruturas de Estado.

Neste artigo, nós escrutinamos os principais mecanismos utilizados para concentração de capital nas mãos dos capitalistas domésticos, evidenciamos a estreita relação dessa classe capitalista com o Partido-Estado e sugerimos como essa dinâmica se vincula com o regime de acumulação de maneira mais alargada. Nosso objetivo é mostrar como o processo de formação da nova classe capitalista doméstica é uma via de mão dupla - um processo guiado pelo Partido-Estado e sob forte pressão da nova classe - e quais os condicionantes externos e os conflitos de classe que acompanham esse processo. Com isso, nós esperamos contribuir para o debate sobre o papel do Estado no desenvolvimento econômico ao lançar luz sobre uma dimensão muitas vezes ignorada na narrativa sobre o nacional-desenvolvimentismo na China: a relação do Partido-Estado com os capitalistas domésticos emergentes e sua imbricada relação com a acumulação de capital.

Na próxima seção, nós revisamos brevemente a literatura sobre o tema e apresentamos nossa abordagem. Nas três seções subsequentes, são discutidos os três principais mecanismos de concentração de capital em mãos privadas inaugurados após a famosa viagem para o sudeste de Deng Xiaoping: as privatizações de ativos estatais e coletivos (sobretudo durante os anos 1990); as expropriações de terra rural (intensificadas nos anos 2000); e as políticas de inovação autóctone (sistematizadas em meados dos anos 2000), sempre relacionando esses mecanismos com os regimes de acumulação que prevalecem no período. A sexta seção dedica-se ao acelerado processo de financerização com características chinesas que acompanha os regimes de acumulação, bem como aos conflitos internos e externos que emergem da relação entre o poder político e o poder econômico na China. A última seção sumariza nossas principais conclusões e sugere algumas das consequências mais evidentes do fracionamento recente da classe capitalista no país.

\section{DO ESTADO NACIONAL-DESENVOLVIMENTISTA AO ESTADO COMO RELAÇÃO SOCIAL}

Uma nova e ampla agenda de pesquisa tem se desenvolvido em torno da complexa relação do Partido-Estado e a nova classe capitalista doméstica na China. Uma parte significativa desta literatura tem enfatizado a característica do Partido-Estado como 
criador dos novos capitalistas, com estrito controle sobre a nova classe (VAN DER PIJL, 2012, 2017; MCNALLY, 2010; DICKSON, 2008, 2003; SO, 2003; GUO, 2003). Em maior ou menor grau, essa literatura reverbera a noção do Estado nacional-desenvolvimentista weberiano como ator autônomo, racional e dotado de uma burocracia talentosa com visão de longo prazo, coerente e bem-intencionada em relação ao processo de desenvolvimento econômico de maneira alargada. De certa maneira, o Estado se parece nessa literatura com o "ente epistemológico exigido pelas estratégias de desenvolvimento" que Fiori caracterizou para o nacional-desenvolvimentismo latino-americano (FIORI, 2003, p. 101), portanto, descolado dos interesses de classe e das contradições que emergem ao longo da acumulação capitalista.

Tanto para Dickson (2008), que chama essa nova classe de "capitalistas vermelhos", quanto para So (2003), que caracteriza o surgimento de uma "classe capitalista partidária", trata-se de um processo racionalmente articulado pelo Partido para criar capitalistas a partir dos seus próprios rankings ou cooptá-los desde o início do seu surgimento. Ambos oferecem vários fatos estilizados sobre a participação desproporcional de empreendedores nas estruturas políticas dos governos local e central, além de relatarem o processo de enriquecimento das famílias de políticos tradicionais de todos os níveis. Segundo uma pesquisa interna do Partido citada por Dickson (2008, p. 13), 90\% dos milionários chineses são familiares em algum grau de lideranças do Partido. Ele conclui que "os capitalistas chineses estão crescentemente integrados ao sistema político e têm pouco incentivo ou inclinação para mudar o status quo no qual eles têm prosperado" (DICKSON, 2008, p. 28).

Na mesma linha, para van der Pijl (2012, 2017), o Partido-Estado tem se antecipado e guiado a formação de classe, levando à constituição de uma "classe capitalista contida", bastante harmônica na sua relação com o poder político e desinteressada em um processo mais amplo de liberalização política e econômica. Ao contrário, "parece haver uma convergência em reforçar o Estado politicamente, inclusive nas suas linhas autoritárias" (VAN DER PIJL, 2012, p.513). Além disso, a entrada de empreendedores no PCC deveria ser lida como "um sinal de que a classe política pode absorver forças sociais ascendentes nas estruturas que controla" (VAN DER PIJL, 2012, p. 512). Ainda mais enfaticamente, McNally (2010) argumenta que o Partido tem tido enorme sucesso em cooptar seus capitalistas emergentes via benefícios nas privatizações e laços subjetivos de reciprocidade, tornando a burguesia chinesa "profundamente incrustada" (thick embeddedness) no aparato do Partido por links que vão dos interesses materiais objetivos a vínculos afetivos próprios da cultura asiática, via laços de preservação de face e conexões interpessoais ( guānxì, 关系).

O mesmo McNally, em artigo mais recente (MCNALLY, 2017), relativiza o caráter unidirecional do Estado criador. Ele argumenta que a economia política chinesa 
tem sido dirigida por um movimento dialético de modos de governança de cima para baixo centrados no Estado interagindo com modos de empreendedorismo de baixo para cima baseados na competição e no poder dos agentes de mercado. "A China está, portanto, buscando um pacote de políticas que busca fortalecer a capacidade de governança do Estado e as forças de mercado em paralelo", argumenta o autor (2017, p. 1). Essa teria sido uma constante da evolução do que ele chama de "sino-capitalismo": uma acumulação dirigida pelo Estado se desenvolvendo lado a lado com uma rede de empreendedores, competição via mercado e integração na economia global.

McNally (2017) avança em relação à literatura anterior ao apontar as pressões que o Estado sofre dos capitalistas privados. Ademais, problematiza por que essa trajetória foi tão distinta da ex-União Soviética, dado que a China evitou a formação de uma elite econômica oligárquica do tipo russo. Mas tem limitações importantes ao interpretar essa trajetória dialética como algo específico da economia política chinesa e não como uma característica do próprio capitalismo. Ele sugere que essa característica única chinesa provocou "reformas" e "adaptações" do Estado, mais do que tensões e disputas até aqui. A sua principal vantagem teria sido gerar espaço em um sistema autoritário para inovações institucionais e de políticas púbicas. Com isso, o autor ressoa a visão liberal de que o Estado continua sendo o pecado original a ser contido e que, sob condições muito únicas, particulares do sino-capitalismo, pôde se tornar eficiente para a acumulação. Ainda segundo essa visão, os capitalistas privados fazem parte das pressões "botton-up" por mudanças, como se fossem agentes descoordenados e sem poder econômico desproporcional.

$\mathrm{Na}$ abordagem empregada neste artigo, a relação entre o político e o econômico é uma relação de codeterminação e interdependência, e os modos de exercício do poder do Estado são vistos como resultado de uma relação social complexa e historicamente determinada pelas formas que o capital assume e profundamente imbricados com o regime de acumulação vigente (e.g., JESSOP, 2008). Estado e economia são aqui percebidos enquanto formas da relação capitalista, exigindo, portanto, que sejam pensados em conjunto e como um só processo histórico-concreto. Seguindo as leituras originais de Fiori sobre o debate derivacionista alemão a respeito do Estado nas suas reinterpretações marxistas, e especificamente a leitura que ele faz de J. Hirsch,

a proposta é que se pense o Estado como dimensão do capital em geral e a valorização como um processo econômico e político, a um só tempo. Nesse sentido, Estado e economia são pensados sob a perspectiva da necessidade, dos limites e da forma da ação estatal nos vários momentos e contextos do desenvolvimento capitalista. (FIORI, 2003, p. 106) 
Apesar da enorme particularidade histórica chinesa - a transição muito recente de uma acumulação planificada sob o regime maoísta para a integração ao capitalismo global via um regime de capitalismo de Estado -, o Estado chinês não está descolado das lutas concretas das classes em formação e em transformação. Os mecanismos escolhidos para concentração de capital e de riqueza em mãos privadas não foram decisões blindadas no alto escalão do Partido-Estado, mas estiveram sob pressão e codeterminação da nova classe privilegiada. Em outros termos, as formas institucionais que o Partido-Estado usou para apoiar a classe capitalista são resultado das lutas e tentativas de dominação constitutivas do próprio capital. Com isso, no próprio processo de formação da nova classe capitalista sob orientação do Partido-Estado, esse mesmo poder político centralizado é constantemente impactado e formado pelas novas frações de classe e pelos embates comas classes oprimidas.

Ao mesmo tempo, e ao contrário da retórica liberal, não se trata de um processo de enfraquecimento do Estado enquanto o setor privado se fortalece. Longe disso, o processo de expansão do poder econômico e da nova classe capitalista foi tanto causado pelo quanto o causador do processo de fortalecimento e ressignificação do poder político do Partido-Estado sob novos regimes de acumulação - um processo que veio, visivelmente, acompanhado por tensões externas crescentes. Foi a contínua, mesmo que parcial, superação das contradições geradas por essa relação tensa e simbiótica, acompanhada das respostas às pressões competitivas externas, que permitiram que o processo de desenvolvimento capitalista avançasse até aqui.

As três próximas seções se dedicam a detalhar os principais mecanismos de concentração de capital que permitiram o rápido surgimento de uma classe capitalista doméstica: as privatizações, as expropriações de terra e as políticas de inovação autóctone. Além disso, evidenciam como esses mecanismos estão imbricados com o regime de acumulação, com as lutas de classe e com as disputas por poder externas.

\section{PRIVATIZAÇÃO PARA OS DE DENTRO E OS CONTORNOS DO CAPITALISMO DE ESTADO COM CARACTERÍSTICAS CHINESAS}

As privatizações e a abertura de capital de empresas estatais e coletivas a partir de meados dos anos 1990 foram o primeiro movimento massivo de concentração de capital em mãos privadas na China desde a revolução de 1949. Inauguradas com o slogan político de “segurar as grandes, deixar as pequenas irem" (zhuādàfàngxiăo, 抓大放 小), as privatizações implicaram em um movimento amplo e diverso de reorganização da estrutura da propriedade industrial. Com isso, foi desencadeado o surgimento de uma classe capitalista doméstica, o posicionamento estratégico das grandes empresas 
que permaneceram estatais, a consolidação de um sistema de poder ao mesmo tempo centralizado e com alto grau de autonomia provincial, e o desmonte do antigo sistema de seguridade social e pleno emprego urbano. Esse movimento, portanto, lançou as bases do capitalismo de Estado e do regime de acumulação puxado pelo investimento e pelas exportações que se consolidam a partir de então.

Para os novos capitalistas que se tornaram proprietários dos ex-ativos estatais, as privatizações (ou as políticas de "reestruturação"2) foram feitas de maneira absolutamente favoráveis, num processo que muitas vezes se pareceu mais com a transferência de ativos do que propriamente com a venda. Os beneficiários foram agentes com conexões prévias com as empresas, sobretudo ex-gerentes das fábricas e lideranças políticas locais. Geralmente, eles próprios precificavam o valor dos ativos, o que implicava em preços irrisórios ou muito baixos, perdão de dívidas e crédito subsidiado para os compradores sem capital prévio -um processo que, na literatura, foi resumido como uma “privatização para os de dentro”. Há inclusive inúmeros registros de ex-gerentes ou lideranças que não desembolsaram nada, tendo levado a compra adiante por meio de empréstimos a serem pagos com a lucratividade futura da própria empresa privatizada (LAU, 1999; LI e ROZELLE, 2004; HONG, 2004; CHEN, 2006; MCNALLY, 2010).

Com as "privatizações para os de dentro", a estrutura da propriedade industrial mudou radicalmente na China. Apesar dos notórios problemas estatísticos e da enorme quantidade de capital misto, estima-se que o setor estatal tenha hoje um tamanho equivalente ao setor privado em termos de produção industrial e de investimentos em ativos fixos. A fatia da propriedade estatal e coletiva na produção industrial caiu de 90,2\% em 1990 para 27,5\% em 2011 (último ano com metodologia comparável), ao passo que a fatia das empresas privadas domésticas saltou de 5,4\% para $29,9 \%$ no mesmo período (NBS, vários anos). A mesma trajetória se deu do ponto de vista de investimentos em ativos fixos: a fatia estatal e coletiva caiu de 72,6\% em 1994 para $27,6 \%$ em 2015 , ao passo que a fatia privada passa de $11,5 \%$ para $30,5 \%$ (Gráfico 1 ). De toda forma, a posição estratégica das empresas estatais remanescentes, tanto do ponto de vista econômico quanto geoestratégico, continua conferindo ao Partido-Estado o comando da acumulação, conforme apontaremos a seguir.

\footnotetext{
2 O PCC sempre se opôs ao termo "privatização" e usa, em seu lugar, a expressão "reestruturação" de empresas estatais. O Partido-Estado também nunca fez da venda de ativos estatais uma política oficial coerente, e não houve uma legislação nacional para regular o processo além de algumas poucas linhas gerais intencionalmente pouco claras. Na ausência de uma regulação nacional, as autoridades locais e provinciais foram deixadas com um considerável poder discricionário para decidir como a propriedade industrial deveria ser transferida para mãos privadas (CHEN, 2006; CAO, 2001).
} 


\section{Gráfico 1 - Investimentos em ativos fixos por tipo de propriedade (em \% do total)}

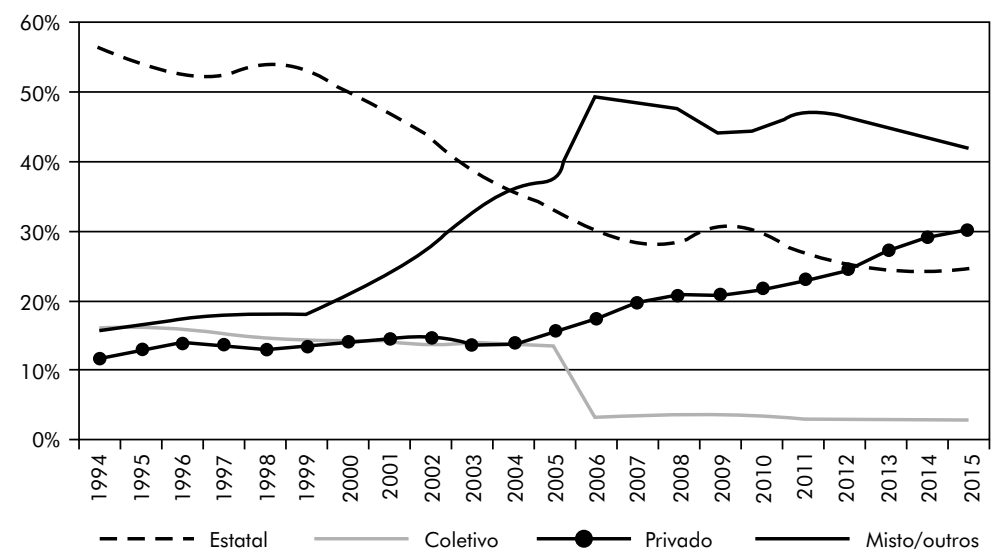

Nota: propriedade mista/outras inclui: limited liability, share holding units, emprego próprio e empresas estrangeiras.

Fonte: Elaboração própria com base em dados de NBS, vários anos.

Nos anos iniciais das reformas, e em números absolutos, as empresas estatais e coletivas caíram de 118 mil para 34 mil entre 1995 e 2003, e cerca de 50 milhões de postos de trabalho foram fechados no setor estatal nesses oito anos (CHAVANCE, 2017), levando a um aumento expressivo na informalidade. O discurso oficial chinês é de que as privatizações tiveram impacto suave sobre as condições de vida dos trabalhadores dado que os demitidos pelas empresas estatais e coletivas encontraram novos postos de trabalho graças ao dinamismo da economia. Porém, o que de fato a maioria encontrou foi, acima de tudo, alguma atividade no setor informal, que passou de $60 \%$ do mercado de trabalho urbano desde 2010 (LEE, 2016), uma pré-condição para um mercado de trabalho com "oferta ilimitada" de mão de obra.

As revoltas urbanas que eclodem na China nesse contexto foram chamadas de "protestos por desespero" na tipologia desenvolvida por Lee (2007). Trata-se de um conjunto de manifestações de ex-funcionários estatais e de empresas coletivas que vão às ruas de maneira espontânea, desorganizada e localizada, com fraco potencial de levar a uma escalada das revoltas no âmbito nacional, mas fortemente ancorados no discurso maoísta de direitos sob o socialismo e sobre a propriedade coletiva. Esses protestos por desespero também foram causados pela acelerada mercantilização dos serviços públicos, sobretudo saúde e educação, dado que as privatizações também implicaram no desmonte do dānwèi (单位), o antigo sistema socialista de proteção social urbano ancorado no emprego estatal. Ele determinava que boa parte da proteção social para trabalhadores urbanos era responsabilidade das empresas estatais. Esse vácuo na proteção social só passou a ser seriamente endereçado na segunda metade 
da década de 2000, após intensos conflitos e mobilizações variadas promovidas pela classe trabalhadora precarizada.

Do ponto de vista do Partido-Estado, as privatizações não implicaram no enfraquecimento do poder político na China. Muito ao contrário, elas levaram à consolidação de empresas estatais estrategicamente posicionadas, controlando os nós da acumulação (inclusive com forte ação anticíclica) e buscando garantir o controle de fontes de recursos naturais fora do país. Com tal política de "reestruturação", as grandes estatais enxugaram dramaticamente suas responsabilidades sociais e se concentraram nas indústrias pilares para uma estratégia de crescimento puxada pelos investimentos, sobretudo em setores de energia, petroquímica, siderurgia, telecomunicações e bancário. São elas que lideram hoje boa parte dos investimentos externos chineses. Dessa forma, firmam-se os contornos do capitalismo de Estado com características chinesas: diversidade de regimes de propriedade e concorrência intercapitalista sob forte direcionamento do Estado e mercantilização acelerada da força de trabalho urbana previamente treinada no regime de fábrica.

Se, do ponto de vista econômico, a privatização está alinhada com o regime de acumulação, do ponto de vista político ela faz parte do "grande compromisso" firmado por Deng Xiaoping em 1992, três anos após o embate que culminou com o massacre da Praça da Paz Celestial (Tiananmen). Em 1989, o Partido havia sido diretamente confrontado pela burguesia emergente que buscava novas fronteiras para acumulação (WANG, 2009; VAN DER PIJL, 2012). Dentre os estratos participando do movimento social de 1989 estavam grupos de interesse que tinham se beneficiado da descentralização dos anos 1980 e que vinham pressionando por privatizações e reformas mais radicais (WANG, 2009, p. 31). Três anos depois, quando Deng firma o "grande compromisso" e assegura o monopólio político do Partido com apoio das forças armadas e dos capitalistas do sudeste do país (VOGEL, 2012), a acumulação de capital ganha os contornos que conhecemos hoje, com abertura controlada pelo Estado para o capital estrangeiro e atendimento às demandas dos capitalistas domésticos. Portanto, ao mesmo tempo em que as privatizações permitiram a diversificação dos tipos de propriedade e o estabelecimento de uma concorrência intercapitalista controlada, elas também atenderam às pressões que se avolumavam desde os anos 1980 por concentração de capital entre a elite política e econômica emergente.

Essa nova burguesia também pressionou pela abertura capital das grandes corporações estatais sob administração central (a maioria hoje de capital aberto). Fundos de investimentos e novas holdings foram estabelecidos para permitir o processo de venda das ações e se transformaram rapidamente emveículos de formação de grandes fortunas (WANG, 2015; CAO, 2001; LAU, 1999). É essa mesma fração da burguesia financeirizada que lidera hoje os pleitos por contínua reforma das estatais chinesas e 
por liberalização financeira e da conta de capitais, conforme vamos explorar na seção cinco. Antes disso, vamos detalhar na seção seguinte outro mecanismo de "acumulação primitiva" essencial no padrão de crescimento puxado pelos investimentos: a "epidemia” de perda de terras por uma massa expressiva de camponeses.

\section{EXPROPRIAÇÃO DE TERRA, CRESCIMENTO PUXADO PELO INVESTIMENTO E OS CAPITALISTAS DAS GRANDES OBRAS}

A principal mudança na configuração social das zonas rurais da China ao longo da década de 2000, a expropriação da terra em larga escala dos camponeses, foi um segundo e poderoso mecanismo de concentração de capital e promoção dos capitalistas domésticos. Na virada do século, o país passou pelo que Riskin (2008) chamou de uma “epidemia" de expropriações, estimulada tanto pela expansão do mercado imobiliário (inflado pela rápida urbanização e pela especulação) quanto pelas necessidades fiscais dos governos locais. Estima-se que um total de 70 milhões de agricultores tenham perdido suas terras até 2006 e receberam indenizações "grosseiramente inadequadas", segundo Riskin (2008). Os estudos de caso tentando medir o valor médio nacional das indenizações sugerem que as compensações aos agricultores têm ficado entre 1\% e $10 \%$ do preço pago por quem ficou com a concessão da terra (ver TAO et al., 2009; ZHOU, 2009; GUO, 2003). Segundo o governo, a área agricultável do país encolheu para 1,827 bilhão de $m u$ em 2009, apenas ligeiramente acima do patamar de 1,8 bilhão de $m u$ (120 milhões de hectares) determinado como o mínimo necessário para a segurança alimentar nacional.

Ainda que a terra rural seja propriedade coletiva na China, os governos locais têm a prerrogativa de expropriar um determinado número de agricultores anualmente com base no "interesse público". Legalmente, a terra rural pode ser convertida em urbana sob três alegações distintas: uso para bens públicos (transportes, projetos de irrigação e energia, saúde e educação), uso industrial e desenvolvimento de negócios (incluindo construções comerciais e imobiliárias). Dado o acelerado processo de urbanização, as cotas de conversão anuais determinadas pelo governo central têm sido explicitamente ignoradas (ZHOU, 2009). Com os preços da terra em franca disparada nas cidades ${ }^{3}$,

\footnotetext{
3 A legislação que rege a propriedade da terra urbana é distinta da rural. Nas zonas rurais, não há concentração de terra, em parte, graças ao regime coletivo. Nas cidades, o mercado imobiliário funciona como na maioria dos países capitalistas. Nacionalmente, a terra continua sendo coletiva, mas a posse privada é permitida no caso dos imóveis urbanos, transacionados hoje segundo preceitos de mercado (inclusive levando às bolhas imobiliárias nas grandes cidades no final da década de 2000). Feita a transformação da terra rural para urbana, tudo que for construído na terra "concedida" ao empreendedor urbano pode ser transacionado como propriedade privada.
} 
os governos locais têm utilizado seu controle sobre a terra rural como uma forma de incrementar o orçamento e de atrair negócios para suas regiões.

Desde a reforma fiscal de 1994, que recentralizou grande parte da arrecadação ${ }^{4}$, os governos locais têm buscado superar as restrições orçamentárias de inúmeras maneiras, uma delas via as expropriações de terras a fim de aliviar suas necessidades fiscais. Tao et al. (2009) reportam estudos de caso segundo os quais a receita fiscal relacionada à expansão da fronteira urbana e expropriação de terras representava entre 30\%-60\% da arrecadação total nas esferas sub-provinciais (municipalidades), em meados dos anos 2000. Na tentativa de melhorar a condição fiscal e o desempenho econômico da municipalidade (fundamental na carreira política), essas autoridades têm se mostrado particularmente interessadas em expandir negócios em sua jurisdição, especialmente nos ramos industriais e residenciais. Os projetos de expansão imobiliária são vistos como importantes do ponto de vista da arrecadação porque geram altos (e geralmente rápidos) impostos sobre negócios. Entretanto, como o imposto sobre a propriedade é muito baixo na China, uma vez que as vendas estejam concluídas, as receitas dos governos locais caem rapidamente. Por outro lado, projetos de manufatura tendem a ter um período de maturação mais longo, mas uma vez que as fábricas estejam funcionando, a arrecadação aumenta gradualmente. Esses dois projetos são, portanto, vistos como fontes complementares do ponto de vista da receita fiscal, e os descontos na oferta da terra (especialmente aquela recém-transformada de rural para urbana) para as empreiteiras são o instrumento mais comum utilizado na competição regional por investimentos.

A relação simbiótica que se estabelece em meados dos anos 2000 era muito clara. De um lado, empreendedores pressionando os governos locais na tentativa de expandir suas possibilidades de acumulação via transferência das terras. De outro, governos locais engajando-se em negociações pessoais para garantir a expansão da arrecadação e benefícios pessoais (TAO et al., 2009). Em 2003, dos 200 mil hectares rurais convertidos em urbanos, apenas 30\% foram feitos por meio de licitações públicas, contra $70 \%$ negociados individualmente entre os governos locais e os empreendedores. Os preços pagos pela concessão da terra transformada em urbana variam dependendo da localidade. Em alguns casos mais radicais, ao redor do Rio das Pérolas, os autores relatam que o preço pago por algumas concessões foi virtualmente zero.

O resultado tem sido um sistema distorcido de apropriação da terra transformada em urbana que beneficia as empreiteiras e os empreendedores industriais, alivia

\footnotetext{
4 A reforma tributária de 1994 determinou que o governo central ficaria com $75 \%$ da arrecadação do o imposto sobre valor agregado (IVA), a principal fonte de receita fiscal, contra $25 \%$ reservado para o governo local. O sistema recentralizou as receitas, mas manteve os gastos inalterados, criando um importante descompasso fiscal nas contas locais (ver SHUE e WONG, 2007, para mais detalhes).
} 
o orçamento local e deixa o custo da rápida urbanização para os ex-camponeses. A concentração de renda via mercado imobiliário das grandes cidades esteve, na virada do século, entre os principais mecanismos de aumento das desigualdades na China (GALBRAITH et al., 2008). Os autores relacionam a especulação imobiliária também às mudanças na legislação sobre fluxo de capitais no país que, desde 2002, apesar da manutenção do controle sobre a entrada de capitais, acabou com os limites de moeda estrangeira que pode ser mantida em caixa pelas empresas chinesas.

Do lado dos camponeses, a compensação recebida pela expropriação da terra onde trabalham é, normalmente, uma pequena parte do preço pago pelo empreendedor (entre $1 \%$ e 10\%). Os conflitos em torno da terra foram, ao longo da década de 2000, a principal causa das dezenas de milhares de "incidentes de massa", como oficialmente são chamadas as mobilizações e os conflitos com a polícia, em função da relação histórica entre direito de uso da terra e proteção social ${ }^{5}$. A partir de 2009, autoridades anunciam que uma nova lei regulando as expropriações está sendo preparada, tendo em vista especialmente garantir indenizações mais justas aos camponeses e preservar a pequena área agricultável per capita do país (CHINA, 2009; LAND, 2009; GOVERNMENT, 2009).

A expropriação de terra está também intimamente ligada às revoltas do trabalho pós-2000, principalmente às grandes greves das cidades da costa chinesa. São esses trabalhadores que deixam temporária ou permanentemente suas terras que passam a ocupar os postos nas fábricas-dormitório das províncias costeiras. Na tipologia de Lee (2007), eles são os responsáveis pelos “protestos contra discriminação", conflitos e greves em massa contra a ausência de direitos trabalhistas e sociais, atrasos ou irregularidades no pagamento de salários, jornadas de trabalho excessivas, condições de trabalho precárias etc. Esses trabalhadores sem registro de moradia (hukou, 户口) configuram cidadãos de segunda classe nas cidades, com salários entre $30 \%-40 \%$ inferiores aos trabalhadores com registro urbano, e sem direitos sociais básicos nas cidades onde trabalham (sem acesso à saúde ou escolas públicas, por exemplo). Não só o número de greves cresceu exponencialmente, chegando a uma média de 50 por mês segundo a autora, como o ativismo cresceu em visibilidade e capacidade de articulação na direção de um movimento ampliado e com pretensões nacionais. $\mathrm{O}$ exemplo final disso foram as famosas greves de 2010 que atingiram dezenas de milhares de traba-

\footnotetext{
A distribuição igualitária da terra entre a população rural era a principal proteção social desde o fim das comunas. $\mathrm{O}$ acesso universal foi um impedimento à formação de uma classe de pobres sem terra, como é o padrão de tantos países subdesenvolvidos, e vinha sendo a principal garantia de subsistência para trabalhadores rurais em face à inexistência de um sistema de proteção social. Não apenas os migrantes podiam, em tese, retornar à sua terra em casos de falta de trabalho nas cidades, como velhos e doentes podiam encontrar algum tipo de proteção contra pobreza e destituição extremas (RISKIN, 2008).
} 
lhadores nas fábricas da Honda, Toyota, Foxconn e muitas outras, e que resultaram em aumentos salariais expressivos (LEE, 2016). Desde 2010, além do crescimento no volume de ativismo, alguns autores argumentam que é possível observar a maturação e radicalização do movimento trabalhista, com demandas que deixaram de ser defensivas e se tornaram mais ofensivas e mais políticas, pleiteando o direito à organização sindical autônoma, por exemplo (CHEN e TANG, 2013).

Se os dois mecanismos de concentração de capital analisados até aqui (privatizações e expropriação de terras) carregavam um elevado potencial de acirramento do conflito de classe capital-trabalho, a legalidade do terceiro, e mais recente mecanismo, tem sido questionada, sobretudo, internacionalmente. Trata-se de um cenário de crescente tensionamento externo que se configura pari passu com a consolidação de diferentes frações da classe capitalista. É o que vamos discutir na seção seguinte.

\section{TECNOLOGIA AUTÓCTONE, COMPETIÇÃO INTERNACIONAL E CRESCIMENTO PUXADO PELO CONSUMO COM FINANCEIRIZAÇÃO}

O terceiro movimento de rápida concentração de capital e que ganha fôlego ao longo da década de 2000, é bastante distinto dos dois movimentos anteriores. Nós o chamamos de apoio à tecnologia autóctone, buscando sumarizar um amplo conjunto de políticas de estímulo às inovações e à formação demarcas e tecnologias chinesas globalmente líderes. Ao contrário dos dois instrumentos apresentados nas seções anteriores, essas políticas deveriam ajudar a fundar um novo regime de acumulação que desse maior papel ao consumo interno e fosse marcado pela subida do país nas cadeias globais de valor, fortalecendo firmas líderes chinesas detentoras da marca e com o controle das cadeias. Ademais, contrariamente às privatizações e às expropriações de terra, a legitimidade destas políticas não é contestada domesticamente. A proteção do Estado às firmas nacionais e os mecanismos de apoio que as acompanham não são objeto de luta de classe e mobilização das massas. De outro modo, o apoio do Estado para a emergência de marcas chinesas está associado ao ideal de construção de uma China forte que não se torne objeto de controle externo, o que em geral encontra forte apoio doméstico. Conforme veremos ao final desta seção, em função do desafio competitivo com as marcas estabelecidas, essas políticas têm encontrado forte resistência e pressão externa vinda dos países centrais, notadamente dos Estados Unidos e Europa.

As políticas de apoio à emergência de marcas domésticas ganharam impulso em 2006 em função do programa de “inovação autóctone” (zizhǔchuàngxīn, 自主创新) lançado pela administração Hu Jintao e Wen Jiabao para promoção de marcas e inovações chinesas em setores intensivos tecnologicamente. Ainda que não seja algo pro- 
priamente novo no conjunto de políticas públicas na China, o programa configurou um plano nacional envolvendo vários ministérios em mega projetos ambiciosos. Ademais, tem usado tanto o mercado interno quanto a internacionalização das estatais chinesas (via uso de equipamentos, componentes e tecnologia chinesa no exterior) para gerar demanda por produtos e inovações desenvolvidos na China. E fundamental para este artigo: o programa tem se desenvolvido em estreita relação com (e sob influência e pressão dos) capitalistas domésticos.

Dois instrumentos têm sido muito utilizados como políticas de inovação baseadas na demanda doméstica: compras públicas e padrões técnicos, ambos internacionalmente muito contestados pelos competidores. Equivalentes a cerca de $2 \%$ do PIB chinês, as compras governamentais foram rapidamente percebidas como instrumento de impulso das marcas nacionais. Na década de 1990, durante a instalação de redes de comunicação de fibra ótica nos sistemas dos bancos, alfândega, coleta de impostos, postos de saúde, hospitais e universidades, o governo determinou a necessidade de contratação de padrões tecnológicos e produtos de firmas chinesas. A principal beneficiada pelo programa foi a Legend, gigantesca holding que hoje detém, dentre muitas empresas, a Lenovo, uma das principais marcas chinesasde eletroeletrônicos.

Também a escolha de padrões técnicos pelo Estado tem sido empregada com frequência no setor de telecomunicações para estimular as firmas chinesas. Tanto a Huawei quanto a ZTE - as duas maiores marcas chinesas de telecomunicações - foram favorecidas pela escolha do padrão V5.1, utilizado em sistemas de comutação para centrais telefônicas de grandes capacidades e desenvolvido conjuntamente pelas duas firmas. Até meados da década de 1990, esse padrão estava restrito ao interior rural da China, onde essas empresas conseguiam penetrar sem competição estrangeira. Foi nesse momento que o governo chinês estipulou que todos os novos sistemas de comutação vendidos no mercado doméstico deveriam ser compatíveis com a interface V5.1. Como a maioria das firmas estrangeiras não produzia sistemas nessa interface, a expansão das marcas locais foi expressiva até que os competidores de fora conseguissem se adaptar (ZHAO et al., 2007; NOGUEIRA, 2015).

A partir de meados dos anos 2000, são recorrentes os relatos de pressão das fabricantes chinesas por proteção e defesa da tecnologia autóctone via, por exemplo, padrões técnicos para celulares. Em 2009, depois de intensa disputa entre operadoras domésticas, fabricantes estrangeiras e fabricantes nacionais (sobretudo Huawei, ZTE e Lenovo), o governo selecionou o TD-SCDMA como o padrão técnico de celulares de terceira geração (LEE et al., 2012). O padrão foi desenvolvido por um instituto de pesquisa estatal (Datang) e sofreu aberta resistência das fabricantes estrangeiras (sobretudo Motorola e Nokia) e das operadoras domésticas. Em 2009, o 3G TD-SCDMA não apenas foi adotado nacionalmente, como veio acompanhado de um programa 
nacional de apoio via linhas de crédito e subsídios para as fabricantes nacionais (GAO e LIU, 2012; NOGUEIRA, 2012).

A reação dos países centrais a esses instrumentos tem sido intensa, acirrando a competição internacional por poder e dinheiro conforme o Estado e as firmas chinesas se tornam globalmente poderosos. O governo chinês chegou a demandar um selo específico de inovação autóctone como pré-requisito para participação em compras públicas em 2009. Mas a medida foi revogada em 2011, depois de ameaças do governo estadunidense (NOGUEIRA, 2015). Da mesma forma, enquanto ainda vigorou como proposta, o Tratado Trans-Pacífico (TPP) trouxe capítulos específicos que proibiam, por parte dos países signatários, o uso das compras públicas como política de inovação. Ao longo dos seus vários capítulos, o rascunho inicial do TPP era um caso explícito de proibições e vetos ao conjunto de políticas industriais, de proteção do mercado interno e de apoio à inovação que a China tem levado a cabo para promover suas indústrias e suas tecnologias essencialmente domésticas.

\section{DA "FINANCEIRIZAÇÃO COM CARACTERÍSTICAS CHINESAS" À PRESSÃO PELA LIBERALIZAÇÃO: TENSÕES E DISPUTAS COM O FRACIONAMENTO DA CLASSE CAPITALISTA DOMÉSTICA}

Possivelmente, uma das características que hoje mais fortemente distingue o regime de acumulação da China em relação a outras economias (centrais ou periféricas) está na sua relativa autonomia em relação à financeirização sob hegemonia do dólar. O capitalismo financeiro, que determina ritmos e modos de acumulação dos EUA à Europa, da América Latina à África desde a onda neoliberal iniciada nos anos 1980, não penetra na economia chinesa com a mesma intensidade. Em grande parte, isso é impedido pelo sistema financeiro essencialmente estatal e pelo forte controle da conta de capitais imposto pelo Partido-Estado, o que impõe limites ao fluxo e à especulação de curto prazo (VERMEIREN e DIERCKX, 2012).

Isso não significa, entretanto, que a economia chinesa não tenha assistido a uma expansão da financeirização nas últimas décadas. Ao contrário, todos os três períodos da acumulação de capital chinesa que descrevemos anteriormente (da ampliação da base de acumulação ao crescimento puxado pelos investimentos até a tentativa atual de um crescimento puxado pelas inovações) vieram acompanhados de uma expansão muito expressiva das finanças. Trata-se, como tudo, de uma "financeirização com características chinesas". Ao contrário da globalização financeira sob o dólar, a financeirização chinesa não deslocou as empresas produtivas das suas atividades originais, transferindo uma fatia do seu faturamento diretamente ao mercado financeiro, sem 
passar pela produção (como na crítica de François Chesnais à "mundialização financeira"). Da mesma forma, a financeirização chinesa também não veio compensar a queda nos salários por meio do endividamento das famílias, para assim assegurar o consumo mesmo sem massa salarial (como na crítica de Costas Lapavitsas à "expropriação financeira" nos EUA e na Europa).

A financeirização com características chinesas mobilizou e canalizou recursos domésticos via o sistema financeiro para as grandes obras de infraestrutura e urbanização. Também, ao mesmo tempo, abriu canais para penetração dos capitalistas privados nos altos circuitos financeiros e especulativos, o que é a causa da atual bolha do mercado imobiliário. Tudo com intensa limitação sobre as conexões do sistema financeiro doméstico em relação ao poder do dólar no sistema monetário internacional. Isso não significa que a estrutura desse sistema esteja toda sob controle das autoridades nacionais, como a enorme expansão do sistema financeiro na sombra (shadow banking), que atende empresas privadas com acesso limitado ao sistema bancário estatal, bem mostra (CINTRA e SILVA, 2015). Porém, essa estrutura é fortemente regulada em relação ao controle estrangeiro sobre o sistema.

Esse processo de financeirização essencialmente controlado pelo Partido-Estado surgiu em meados dos anos 1990 e ganhou impulso espetacular em meados dos anos 2000. Enquanto o Partido-Estado mantém controle estrito sobre a conta de capitais, os capitalistas privados têm penetrado nos circuitos financeiros da China por duas vias: (i) participação acionária nas corporações estatais via compra direta de ações, participação em holdings financeiras, fundos de investimentos e seguradoras; e (ii) via o tripé infraestrutura, especulação imobiliária e novas plataformas financeiras como os chamados produtos estruturados - special purpose vehicles (SPV).

A financeirização das empresas estatais tem sido um processo guiado pelo PartidoEstado sob intensa pressão dos novos capitalistas domésticos, levando ao que Wang (2015) chama de "share holding state" (Estado acionista). Praticamente todas as grandes estatais foram transformadas em corporações de capital aberto. Essas empresas têm passado por um processo acelerado de securitização na última década, especialmente como forma de levantar capital para financiar projetos de infraestrutura dentro e fora da China e dar vazão às pressões domésticas por novas fronteiras de acumulação de capital. O objetivo é ampliar o acesso a instrumentos financeiros e de governança corporativa e pressionar diretores e conselhos de administrações por resultados sem reduzir o controle do Partido-Estado (WANG, 2015). Em outros termos, tornar as SOE competitivas internacionalmente, com abundante acesso a capital, sem perder a orientação estratégica do Partido-Estado.

Os governos locais, da sua parte, têm feito um uso agressivo de produtos financeiros de risco para financiar a urbanização, principalmente via um tipo específico de 
special purpose vehicle chamado de plataformas de financiamento local (local financing plataform, LFP). Em 2013, foram contabilizadas mais de sete mil LFP, cujos empréstimos representavam 40\% das dívidas dos governos locais (WANG, 2015). As LFP utilizam diferentes ativos estatais como garantias - de leasing de serviços públicos a fatias em empresas estatais, receitas de impostos e, sobretudo, terra hipotecada. Esses produtos estruturados são então recompostos em produtos securitizados vendidos pelos bancos aos clientes com muito capital.

Esse processo de financeirização, entretanto, não veio sem contradições e tensões. De um lado, o Partido-Estado tem na financeirização com características chinesas um pilar não só da sua estratégia de desenvolvimento nacional, como da projeção do seu poder político e econômico globalmente. De outro lado, vários novos "capitalistas vermelhos" chineses estão pressionando pela liberalização financeira sob hegemonia do dólar como forma de ganhos financeiros imediatos.

A “financeirização à chinesa” está centrada na tentativa de criação de um sistema monetário menos dependente do dólar e mais baseado em instituições multipolares sob controle ou influência chinesa (AGLIETTA e BAI, 2017). Não estamos falando na existência de um plano estruturado para substituição do dólar como moeda hegemônica do sistema, mas de tentativas de ampliação do espaço de manobra do capital chinês pelo mundo com menor subordinação ao poder da moeda norte-americana. Isso inclui a consolidação e expansão dos bancos de desenvolvimento como financiadores em última instância (como o Asian Infrastructure Investiment Bank), esperando-se que os investimentos em infraestrutura financiados por tais bancos sejam um motor dinâmico do crescimento global (a "Belt and Road Initiative" é a estratégia que amarra todas as pontas). Além disso, inclui também a ampliação do uso internacional do renminbi em transações comerciais, maiormente de petróleo ${ }^{6}$.

A emergência de um Estado financeirizado nos níveis local e central, no entanto, veio acompanhada da emergência de capitalistas que retiram fatias crescentes das suas remunerações de diferentes tipos de atividades financeiras. Em conjunto com interesses externos, são eles que estão pressionando pela abertura da conta de capitais da China. Em março de 2017, durante a $5^{\mathrm{a}}$ sessão do $12^{\circ}$ Congresso Nacional do Povo, executivos de empresas e dos setores financeiro e de construção civil criticaram abertamente os controles de capitais como instrumentos que dificultam as aquisições chinesas no exterior (CHINA, 2017a). Até o momento, a financeirização chinesa tem mantido autonomia em relação ao poder do dólar justamente por conta do controle de capitais. Entre-

6 A China abriu mercados futuros de petróleo diretamente na sua moeda, portanto negociados em yuan, não em dólar, na Shanghai International Energy Exchange (INE). Trata-se de um claro desafio aos petrodólares, um dos elementos de sustentação do dólar como padrão monetário do sistema internacional (CHINA, 2017b). 
tanto, as pressões internas e externas são fortes, e a expressiva saída de capitais da China em 2016 mostra sua vulnerabilidade aos movimentos especulativos sem regulação. Em 2016, durante limitada tentativa de liberalização, a China perdeu quase meio trilhão de dólares em reservas internacionais (precisamente US\$ 443 bilhões), derrubando o total de reservas para abaixo de US\$ 3 trilhões pela primeira vez desde 2011 (CHEN, 2017).

A tensão social gerada pelo fracionamento da classe capitalista e pela complexificação dos seus interesses tornou-se evidente na luta política doméstica. Desde o lançamento da campanha anticorrupção pelo presidente Xi Jinping, em 2012, os principais opositores políticos do atual líder da China foram presos, além de capitalistas que fizeram fortuna no sistema financeiro. Somente em 2017, meio milhão de pessoas foram punidas (527 mil pessoas) pela campanha, segundo a Comissão Central de Inspeção Disciplinar do Partido, das quais 58 eram quadros do Partido de nível provincial (governador), ministerial ou superior (ZHŌNGYĀNG, 2018). Ao longo da campanha anticorrupção, isso incluiu a prisão de políticos de altíssimo nível e alguns bilionários, oficiais militares, presidentes de grandes empresas estatais, donos de holding financeiras, lideranças de agências reguladoras do sistema financeiro e um dos sete membros permanentes do Politiburo, órgão máximo de poder político do país.

As detenções chegaram, inclusive, às famílias de alguns dos ex-líderes políticos mais importantes, como a família Deng. Wu Xiaohui, marido da neta de Deng Xiaoping, foi preso em junho de 2017 sem acusação formal. Sua prisão vem na esteira de outras prisões de empresários e reguladores do ramo de seguros, possivelmente o mais especulativo na China nos anos recentes, e de uma nova campanha destinada a "limpar o setor financeiro da corrupção". A holding de Wu Xiaohui, chamada Anbang Insurance Group, é uma das maiores do paíse vinha se notabilizando por compras bilionárias de hotéis de luxo pelo mundo. Em novembro de 2016, Wu tentou fechar negócio para compra de hotel em Manhattan com o genro e conselheiro do presidente norte-americano Donald Trump, Jared Kushner (HASS, 2017). O caso é apenas o mais caricato dentre diversos fatos estilizados que se avolumam e evidenciam as conexões de frações do setor financeiro na China com o capital internacional - e que a atual liderança chinesa tenta conter via intensa luta política interna.

\section{CONCLUSÃO}

A consolidação de uma classe capitalista e a relação simbiótica de suas frações com o Partido-Estado estão entre as transformações mais fundamentais da estrutura social chinesa da última década. Isso faz com que a narrativa nacional-desenvolvimentista convencional de que o "sucesso" chinês deve-se à materialização de um Estado we- 
beriano racional e bem-intencionado deva ser problematizada não apenas pelo seu excessivo "nacionalismo metodológico" e desconexão com os condicionantes externos nas trajetórias de desenvolvimento, mas ainda pelo seu descolamento das estruturas sociais e das dinâmicas de classe que conformam a expansão do capitalismo.

Este artigo escrutinou as relações estreitas entre poder político e poder econômico na China, e como os mecanismos de concentração de capital em mãos privadas estiveram imbricados com o regime de acumulação dominante. No primeiro período de concentração, via "privatizações para os de dentro", o Partido-Estado tanto respondeu às pressões para diversificação dos tipos de propriedade quanto fortaleceu o posicionamento estratégico das estatais remanescentes. Isso lançou as bases do capitalismo de Estado com características chinesas, inclusive do ponto de vista da inauguração de um mercado de trabalho urbano com oferta ilimitada de mão de obra. Da mesma forma, a expropriação de terra dos camponeses e a explosão imobiliária e de infraestrutura tanto facilitaram de sobremaneira a emergência dos bilionários chineses, quanto lançaram as bases do crescimento puxado pelos investimentos.

Os conflitos gerados que se avolumaram por essas formas de acumulação primitiva são parcialmente arrefecidos pela "sociedade harmoniosa" da década de 2000 e pela sua tentativa de criação de um Estado de bem-estar social mínimo, um prérequisito do suposto crescimento puxado pelo consumo que se busca também via as inovações autóctones. Entretanto, o fracionamento da classe capitalista, rapidamente acelerado pela financeirização e pela intensificação das suas tentativas de relações com o capital externo, engendrou novas pressões no Partido-Estado, que tem respondido por meio da intensificação do seu aparato repressor, incluindo, entre outras manobras, a campanha anticorrupção do atual presidente Xi Jinping.

Nas interpretações sobre a trajetória de desenvolvimento da China, incorre-se, muitas vezes, no engano de um suposto descolamento do Estado das dinâmicas de formação de classe em função da força do Partido Comunista como agente principal da forma-Estado ali constituída. O que assegura a permanência do Partido, e o que é o seu elemento de continuidade ideológica desde sua fundação até hoje, é a defesa do nacionalismo e da segurança nacional como pré-requisitos para a modernização tecnológica da nação. Isso corresponde, em algum grau, à ideia de "missão" que os weberianos atribuem ao Estado desenvolvimentista. $\mathrm{O}$ erro dos weberianos em geral é supor o total descolamento do Estado em relação às classes, ignorando as dinâmicas sócio-políticas que permitem que, em determinadas circunstâncias, haja arranjos políticos para projetos de desenvolvimento mais ou menos autônomos em relação à dinâmica de poder internacional.

O elemento novo do atual tensionamento entre o poder político e o poder econômico na China são as tentativas de conexões de uma fração da classe capitalista do- 
méstica com o capital internacional. O nacionalismo do Partido Comunista da China e a sua narrativa de modernização como um projeto de fortalecimento nacional é o elemento de continuidade e o amálgama mais profundo que manteve a coerência ideológica em face ao desmonte da estrutura socialista. Seu questionamento por parte de uma fração da classe capitalista doméstica é, sem dúvida, um elemento de forte tensão para uma estrutura social sob intensa transformação.

\section{REFERÊNCIAS BIBLIOGRÁFICAS}

AGLIETTA, M.; BAI, G. China's 13th five-year plan. In pursuit of a "moderately prosperous society”. CEPII Policy Brief, Paris, Centre D’etudes Prospectives et D’informations Internationales, n. 12, 2017.

BRUNHOFF, S. The state, capital and economic policy. London: Pluto Press, 1979.

CAO, L. Chinese privatization: between plan and market. Law and Contemporary Problems, v. 63 , n. 4 , p. 13-62, 2001.

CHAVANCE, B. Ownership transformation and system change in China. Revue de la Régulation, v. 21, $1^{\circ}$ semestre, 2017.

CHEN, F. Privatization and its discontents in Chinese factories. The China Quarterly, v. 185, p. 42-60, 2006.

CHEN, L. Containing capital outflows. Ideas, Gavekal Dragonomics, 15 fev. 2017.

CHINA's capital control trigger a backlash after scrapped deals. Bloomberg News, 7 mar. 2017, 2017a. Disponível em: <https://www.bloomberg.com/news/articles/2017-03-07/china-s-capital-controls-trigger-a-backlash-after-deals-thwarted>. Acesso em: 12 ago. 2017.

CHINA plans to break petrodollar stranglehold. Asia Times, 21 dez. 2017, 2017b. Disponível em: $<$ http://www.atimes.com/article/china-plans-break-petrodollar-stranglehold/>. Acesso em: 22 ago. 2017.

CHINA urged to reform land expropriation policies.People's Daily, 09 mar. 2009. Disponível em: <http://en.people.cn/90001/90776/90785/6609978.html>. Acesso em: 10 jul. 2017.

CINTRA, M. A.; SILVA, E. B. "O sistema financeiro chinês: a grande muralha”. In: CINTRA et al. (Orgs.). China em transformação: dimensões econômicas e geopolíticas do desenvolvimento. Brasília: IPEA, 2015.

COX, R. Social forces, states and the world order: beyond international relations theory. Millennium - Journal of International Studies, v. 10, n. 2, p. 126-155, 1981.

DICKSON, B. J. Wealth into power: the Communist Party's embrace of China's private sector. New York: Cambridge University Press, 2008.

FIORI, J. L. O vôoda coruja: para reler o desenvolvimentismo brasileiro. Rio de Janeiro: Record, 2003.

GALBRAITH, J.; HSU, S.; ZHANG, W. The Beijing bubble: inequality, trade and capital inflow into China. UTIP Working Paper, The University of Texas inequality Project, n. 50, 2008. 
GAO, X.; LIU, J. Catching up through the development of technology standard: The case of TD-SCDMA in China. Journal of Telecommunications Policy, v. 36, n. 7, p. 531-545, 2012.

GOVERNMENT urged to reform land expropriation. Xinhua, 9 mar. 2009.

GUO, B. Political legitimacy and China's transition. Journal of Chinese Political Science, v. 8 n. 1-2, p. 1-25, 2003.

HASS, B. "Chinese tycoon reportedly caught up in sweeping corruption crackdown". The Guardian, China, 14 jun. 2017. Disponível em: <https://www.theguardian.com/world/2017/ jun/14/chinese-tycoon-reportedly-caught-up-anti-corruption-crackdown-wu-xiaohuianbang >. Acesso em: 18 jun. 2017.

HONG, Z. Mapping the evolution and transformation of the new private entrepreneurs in China. Journal of Chinese Political Science, v. 9, n. 1, p. 23-42, 2004.

JESSOP, B. State power: a strategic-relational approach. Cambridge: Polity, 2008.

LAND use reform is most crucial. China Daily, 17 set. 2009. Disponível em: <http://www.chinadaily.com.cn/cndy/2009-09/17/content_8700976.htm>. Acesso em: 18 jun. 2017.

LAU, W. The 15th Congress of the Chinese Communist Party: Milestone in China's Privatization. Capital and Class, v. 68, p. 51-87, 1999.

LEE, C. K. Against the law: labor protests in China's rustbelt and sunbelt. Berkeley: University of California Press, 2007.

LEE, C. K. Precarization or empowerment? Reflections on recent labor unrest in China. The Journal of Asian Studies, v. 75, n. 2, p. 317-333, 2016.

LEE, K.; MANI, S.; MU, Q. "Explaining divergent stories of catch-up in the telecommunication industry in Brazil, China, India and Korea”. In: MALERBA, F.; NELSON, R. (Eds.). Economic development as a learning process. Cheltenham e Northampton: Edward Elgar Publishing, 2012.

LI, H.; ROZELLE, S. Insider privatization with a tail: the screening contract and performance of privatized firms in rural China. Journal of Development Economics, v. 75, n. 1, p. 1-26, 2004.

MCNALLY, C. A.; WRIGHT, T. Sources of social support for China's current political order: the 'thick embeddedness' of the private capital holders. Communist and Post-Communist Studies, n. 43, p. 189-198, 2010.

MCNALLY, C. A. Rebalancing the economy, refurbishing the state: the political economic logic of sino-capitalism in contemporary China. Revue de la Régulation, v. 21, $1^{\circ}$ semestre, 2017.

NBS - NATIONAL BUREAU OF STATISTICS OF CHINA. China Statistical Yearbook. [On-line] National Bureau of Statistics of China, vários anos. Disponível em: $<$ http://www.stats.gov. cn/english/statisticaldata/AnnualData/>. Acesso em: 18 ago. 2017.

NOGUEIRA, I. "Políticas de fomento à ascensão da China nas cadeias globais de valor". In: CINTRA et al. (Orgs.). China em transformação: dimensões econômicas e geopolíticas do desenvolvimento. Brasília: IPEA, 2015.

PANITCH, L.; GINDIN, S. The making of global capitalism. London: Verso, 2012.

RISKIN, C. Property rights and the social costs of transition and development in China. Economic and Political Weekly, v. 43, n. 52, p. 37-42, 2008. 
SO, Y. The changing pattern of classes and class conflict in China. Journal of Contemporary Asia, v. 33, n. 3, p. 363-376, 2003.

TAO, R. et al. Land leasing and local public finance in China's regional development: evidence from prefecture-level cities. Urban Studies, v. 47, n. 10, p. 2217-2236, 2009.

VAN DER PIJL, K. Is the East still red? The contender state and class struggles in China. Globalizations, v. 9, n. 4, p. 503-516, 2012.

VAN DER PIJL, K. Le transnational et le national dans la formation de la classecapitaliste. Actuel Marx, v. 60, n. 2, p. 75-89, 2017.

VERMEIREN, M.; DIERCKX, S. Challenging global neoliberalism? The global political economy of China's capital control. Third World Quarterly, v. 33, p. 1647-1668, 2012.

VOGEL, E. Deng Xiaoping and the transformation of China. Cambridge, Mass.: Harvard University Press, 2011.

WANG, H. The end of the revolution: China and the limits of modernity. London: Verso, 2009.

WANG, Y. The rise of the 'shareholding state': financialization of economic management in China. Socio-Economic Review, v. 13, n. 3, p. 603-625, 2015.

ZHAO, Z. et al. China's industrial policy in relation to electronics manufacturing. China \& World Economy, v. 15, n. 3, p. 33-51, 2007.

ZHŌNGYĀNG jìwěitōngbào 2017 niánquánguójijiănjiānchájīguānjiliùshěncháqíngkuàng中央 纪委通报2017年全国纪检监察机关纪律审查情况”. Xinhuanet News, 11 de janeiro de 2018. Disponível em: <http://www.xinhuanet.com/legal/2018-01/11/c_1122241376.htm>. Acesso em: 15 jan. 2018.

ZHOU, F. "Land seizure, local government and farmers”. In: DAVIS, D.; WANG, F. (Eds.). Creating wealth and poverty in postsocialist China. Stanford: Stanford University Press, 2009. 